REVIEWS OF DATASETS

Patrick Manning

\title{
The Maddison Project: Historical GDP Estimates Worldwide
}

Review of: The Maddison Project

Author/Compiler: Jutta Bolt, Jan Luiten van Zanden

Repository: http://www.ggdc.net/maddison/maddison-project/home.htm

Date of Posting: 2010

Size: $n / a$

Volume 3-4, No. 1 (2016-2017) | ISSN 2169-0812 (online)

DOI 10.5195/jwhi.2017.46 | http://jwhi.pitt.edu 
The Maddison Project, led by Jutta Bolt and Jan Luiten van Zanden at Groningen University, carries on the task of estimating GDP and population figures during the past two millennia—a project created and long led by Angus Maddison. Maddison (1926-2010), was a professor at Groningen from 1978 to 1997 and founder of the Groningen Growth and Development Centre, which now hosts the Maddison Project Site. The site is divided into two segments: the "Original Maddison Homepage" is the archive of the site left by Angus Maddison at the end of his work in 2009; the "Maddison Project" presents the results of work since 2010 to update data within the same framework. This review addresses elements of both parts of the site. The site is structured rather simply-for instance, neither segment of the Maddison Project site is indexed or searchable, except within the files. Nevertheless, the site documents a major node in studies of world economic history and shows the potential for impressive advance in this area of study.

Original Maddison Homepage: This page was kept up to date until Angus passed away in April 2010. It provides access to his latest writings and data series. The final update of the original dataset was in 2009. Guidelines and cover sheets for the datasets and other materials are posted, dated March 2010, as the site was made into a permanent archive. The site makes it possible to review the trajectory of Maddison's work. He published numerous works on economic change beginning in the 1960s, and by the 1980s had established a connection with Paris-based OECD, the Organization for Economic Cooperation and Development. This resulted in his publication of Two Crises: Latin America and Asia, 1929-38 and 1973-83 (Paris: OECD, 1985), after which he launched his project of documenting and estimating comparative national figures for GDP and population, beginning with The World Economy in the 20th Century (Paris: OECD, 1989). In this work, arguably, he took the baton from B. R. Mitchell, who had pioneered the work of individual scholars to compile national and historical statistics for much of the world.

Of Maddison's successive datasets, only his final 2008 dataset is posted. It is displayed both as a "horizontal file" (with dates on the horizontal axis and places on the vertical axis) and as a "vertical file" (with dates on vertical axis and places on horizontal axis). In each case, as many as 260 spatial units are defined for population figures, while up to 198 spatial units are defined for GDP figures. Both of these are Excel files with sheets for contents, population, GDP, Per Capita GDP, population growth rate, and GDP growth rates - with densest data for population and sparsest data for GDP growth.

On Maddison himself, the site includes a 1994 autobiography, an essay on "Research Objectives and Results, 1952-2002," and his curriculum vitae up to 2005. A clear overview of Maddison's focus on how the West got rich (along with his attention to interactions between the West, Asian regions, and Africa) arises from his short book, Growth and Interaction in the World Economy: The Roots of Modernity (Washington, DC: AEI Press, 2005). This was the Henry Wendt Lecture, delivered in 2001 to the American Enterprise Institute. Also available on the site are materials from ten of Maddison's books and twenty of his articles and papers. In sum, one sees the energy and imagination of Maddison's long effort to fit the world into a European economic perspective. Yet within Maddison's own work, and in the project that succeeds him, one also sees an incremental, persistent though not yet definitive extension of attention to other parts of the world.

The Maddison Project': The Maddison Project was launched in March 2010 by a group of scholars with the aim of supporting an effective cooperation among scholars to continue Maddison's work on measuring economic performance for different regions, time periods and subtopics. The working party was headed by Bart van Ark, Debin Ma, Leandro Prados de la Escosura, and Jan Luiten van Zanden; an Advisory Board of 21 was assembled for the project, all of them leading figures in economic history. These and other scholars organized an Angus Maddison 
memorial conference, held 6-7 November 2010 at the International Institute for Social History in Amsterdam. The conference site includes slides for the keynotes by Nicholas Crafts, Jan Luiten van Zanden, Stephen Broadberry, and Eddy Szirmai.

The directors of the program since 2010 have been Jutta Bolt and Jan Luiten van Zanden. Van Zanden, one of the most active and distinguished of economic historians, served as President of the International Economic History Association from 2009 to 2012. He is based at Utrecht University but with an appointment at Groningen as well. After years of work on Dutch and European economic history, he expanded his studies in recent years to include the Dutch East Indies and Cape Colony. Bolt is a junior faculty member who has assumed convincing leadership in this project. A student in economics at Groningen (PhD 2010), she was associated with the Groningen Growth and Development Centre from 2004. She was present at the transition to the Maddison Project, became postdoctoral researcher from 2011 and assistant professor in economics from 2014. She has conducted research in African economic history since graduate school.

The site includes six working papers that show the range of the project's work, dated from May 2011 to January 2017. They address updates on the post-World War II data (No. 1); Russia's national income, 1913 - 1928 (No. 2); historical national accounts for colonial Java, 1815-1939 (No. 3); and the English money supply, 12701870 (No. 6). Most substantial is No. 4 (2013), summarizing the first update of the Maddison Project by estimating growth rates before 1820. A revised version of this paper appeared in Economic History Review in 2014. ${ }^{1}$

The Maddison Project data set is a single Excel sheet, a "vertical" file with 232 years of observation (allowing for annual observations 1800 - 2010; 15 selected years from 1280 to 1775; and observations at years 1 , 730, 1000, and 1150). On the horizontal axis are roughly 150 individual territories and groups of territories addressing, in order, Europe, "Western Offshoots," Latin America, Asia, and Africa. The dataset, while currently simpler than the 2008 "original" dataset, should be read together with the Bolt-van Zanden commentary, either the 2013 or 2014 version.

The focus of the 2013 update is on GDP per capita before 1820. The "starting point" of the 2013 update is that data were presented only on per capita GDP, with changes in those figures only where better information on GDP had become available. This meant that the population estimates were not revised and were not even included in the 2013 update. (To find total GDP, users can multiply the 2013 per capita GDP by the relevant 2008 population.) This does not mean that there had been study only of GDP levels and not of population. Conferences had been convened in 2003 and 2013, especially by the International Institute of Social History (and including Van Zanden) in attempt to achieve comprehensive updates on world population, but results were insufficiently complete. These conferences showed major advances in historical population estimates for Russia, China, Latin America, and Africa, but none of these were yet definitive, and populations of other regions remained poorly studied.

In the 2013 update, per capita GDP figures are complete for most regions from 1950 -the main exception is the lack of a breakdown within the USSR breakdown to 1990. Prior to that time, documentation is uneven: figures for the larger units in Latin America go back to about 1870; Asian data goes back to 1870 for a few welldocumented places, and estimates for Cape Colony now go back to 1700. Early estimates, up to $1200 \mathrm{CE}$, are shown for Egypt, the Byzantine empire, Iraq, Japan, Spain, England, and northern Italy.

The significance of this work points in several directions. The Maddison Project is certainly not the only effort to collect historical data on economy and population. Indeed, tracing its experience shows a steady consolidation of effort by multiple groups of scholars, and a steady expansion in the geographical, temporal, and 
topical focus of data estimation. Most thoroughly, a full set of estimates has now been completed on post-1950 GDP and population worldwide, according to existing standards. This provides a basis for expanded analysis of the post1950 era: one may hope that these data will clarify differences between the period 1945-1975, with growth and incountry equality, as compared with the post-1975 era, with stagnation and higher in-country inequality.

The greatest current attention in the Maddison Project is in comparison of European and Asian economies from the sixteenth to the nineteenth centuries. Twenty years ago, new theses arose claiming that major Asian economies had grown as rapidly as European economies from the sixteenth to the eighteenth century, until the "great divergence" of the nineteenth century brought an era of European dominance. Since then, Europeanist scholars have expanded research and calculation, raising estimates of European per capita GDP: Stephen Broadberry's work on British economic growth has led the way, and the new results will be forthcoming in the Cambridge Economic History of the Modern World, of which he is editor.

In response, expanded research on Asian economies is now under way. The work is sometimes hindered by scarcity and vagueness of data, but new techniques of analysis may arise. Therefore, one might not be surprised to see, in another decade, a wave of reinterpretation showing the relative strength of Asian economies. In addition, what has been a bipolar debate about Europe and Asia in the world economy is developing more complexity. The work of van Zanden on Java and Broadberry on India shows the growth in global collaboration in place of earlier regional specialization. Growing documentation of the Americas, Africa, Southeast Asia, west and central Asia may lead to interpretations that give more attention to economic interactions.

A further possible evolution is that the Maddison Project data will expand not only in their spatial and temporal coverage, but also in the framework of their analysis. Could the national units be treated in interaction rather than as independent units? In a related point, macroeconomists now argue that National Income (NI) provides a more valuable estimate of national economies than GDP-NI is net of income transfers, measuring the income retained in a country (which may be much less than the income produced in it). One can imagine adding estimates of National Income to the table, especially for recent times.

Current work on the Maddison Project shows interconnection of senior and junior scholars of many different national backgrounds, and linkage of universities and research institutions in Europe, North America, East Asia, and Latin America. Researchers associated with OECD, Penn World Tables, the World Bank, and Hitotsubashi University are linked by this network. The historic focus on European economies remains evident and is in some ways growing, yet the exploration of under-documented regions, time periods, and economic-historical topics. In this research once can see a clear move toward creation of a global community of economic-historical research. It is not yet clear what will be the balance of power and outlook within that scholarly community, but the emergence of data collection and interpretation at this scale is certainly an important development.

\section{NOTES}

${ }^{1}$ Jutta Bolt and Jan Luiten van Zanden "The Maddison Project: collaborative research on historical national accounts,” The Economic History Review 67 (2014): 627-665. 


\section{$(\mathrm{cc}) \overline{\mathrm{EY}}$}

Articles in this journal are licensed under a Creative Commons Attribution 4.0 United States

License.

\section{ULIS D-Soute}

This journal is published by the University Library System of the University of Pittsburgh as part of its D-Scribe Digital Publishing Program and is cosponsored by the University of Pittsburgh Press. 